\title{
Gender, and Satisfaction of Body Image in High School Students of Yucatan, Mexico
}

\author{
Yolanda Oliva Peña, Andrés Santana Carvajal, Manuel Ordóñez Luna, Reyna Cruz Bojórquez \\ Autonomous University of Yucatan, Mérida, Mexico \\ Email: opena@correo.uady.mx
}

How to cite this paper: Peña, Y. O., Carvajal, A. S., Luna, M. O., \& Bojórquez, R. C. (2019). Gender, and Satisfaction of Body Image in High School Students of Yucatan, Mexico. Psychology, 10, 30-45. https://doi.org/10.4236/psych.2019.101003

Received: November 24, 2018

Accepted: January 8, 2019

Published: January 11, 2019

Copyright $\odot 2019$ by author(s) and Scientific Research Publishing Inc. This work is licensed under the Creative Commons Attribution International License (CC BY 4.0).

http://creativecommons.org/licenses/by/4.0/

(c) (i) Open Access

\begin{abstract}
Adolescence constitutes a stage of changes and strong social pressures among peers, to adjust to a standard of beauty in which the perception of body image is of great relevance in comprehensive health behaviors as well as a risk factor for eating disorders. Regarding problem that is our interest to know (Body Image), we use a gender focuses, as the transversal analytical axis of the study, as well as the study of a region with a strong presence of Maya-speakers. Methodology: This is a quantitative, cross-sectional study conducted on 1432 high school students in the eastern part of the state of Yucatan, using a self-administered questionnaire (BSQ and SFS scales), with the prior informed consent of parents and participants. Results: It was obtained that $66.5 \%$ of the students are satisfied with their body image, and $32.7 \%$ are dissatisfied. It was obtained by means of the Kappa index that the perceptions of the body image of the studied students vs the desired body image have a moderate concordance. Significant differences on mean on dissatisfaction with their image were found between men and women $p \leq 0.001$. Conclusions: In the area studied it is shown that gender constitutes a risk factor in which the condition of being the social pressure to adjust to beauty models, impacts regardless of the rural, urban or local culture, in this case of the Mayan zone.
\end{abstract}

\section{Keywords}

Gender, Body Image, Body Dissatisfaction, Students, Mexico

\section{Introduction}

Body image (BI) is "the image that our mind forms of our own body, that is, the way in which our body manifests itself to us". Therefore, the body image is not necessarily correlated with the real physical appearance, being key attitudes and 
valuations that the individual makes of his or hers own body. Those subjects who, when evaluating their body dimensions, express evaluative judgments that do not coincide with the real dimensions present an alteration of the body image (Vaquero, Alacid, Muyor, \& Lopez, 2013).

The perception of the body image from the psychological, cognitive and behavioral point of view is important factor since it predisposes, precipitates and perpetuates the alimentary practices of risk that are present in the disorders of the alimentary behavior and in the muscular dysmorphic disorder, mainly in the adolescent population (Treasure \& Schmidt, 1995).

Raich defines body perception as "a complex construct that includes both the perception we have of the whole body and each of its parts, and the movement and limits of it, the subjective experience of attitudes, thoughts, feelings and valuations..." (Raich, 2001).

Body image is formed in childhood from the interaction with parents, siblings, friends, schoolmates; therefore, whether these interactions were positive or negative will have an impact on the individual's self-esteem (Salaberria, Rodríguez, \& Cruz, 2007). Currently, the culture of beauty and aesthetics has overestimated the perfect image by placing it as a synonym of success. This idea of physical perfection, which leaves aside other important aspects of the human being, is being strongly promoted by fashion and the media and the aesthetic criteria of society. The issue of gender matters, given the roles, imposed the pressure of women to project a body image to be conquered by men and men a corporal figure for conquest, virility (Bourdieu, 2000).

Gender plays an important role in BI and is perceived differently between men and women (Rodríguez, 2012). For example, in women, slimness is positively valued; it is expected that they have broad hips, long legs, large breasts and toned bodies, while in men the gain in weight and musculature is valued (Rocha, 2009; Vázquez et al., 2004). Adolescents (Rodríguez \& Cruz, 2006) are one of the populations most prone to present greater concern for body image.

This cult to the body could be a determining factor that impacts adolescents of diverse ages and socioeconomic levels in a severe way, causing the idea of a perfect body to become very important, because, at this moment of his or hers life, he or her believes and is convinced of that everything can (Horrocks, 1999).

Since "this" is a society where beauty and youth are overestimated above health, it is not surprising that the concern for physical appearance leads young people from all social strata and cultures to carry out practices that endanger their health and his life (Raich, 2004). The different standards of beauty that have been established over time in different societies and times have made body image (BI) become a form of belonging and priority for human beings, and have contributed to greater concern nowadays for the physical aspect and to achieve the current corporal socio-cultural ideal (Míguez et al., 2011; Muñoz, 2014; Vaquero et al., 2013).

This concern for physical appearance and the cult that is given to the body 
remains more or less constant throughout life (Rodríguez \& Cruz, 2006), taking into account the size, size, shape and weight of the body, whole or in its different parts (García, 2004). These characteristics are associated with the mental representation that each individual creates in relation to himself, and encompasses thoughts, values and feelings (Guadarrama et al., 2018).

Body dissatisfaction is often related to low self-esteem; Study confirms that at least one third of self-esteem is related to how positive or negative their self-image is. The negative body image generates interpersonal anxiety, problems in their sexual relations and depression (Otto et al., 2001). As a consequence of this, body image is influenced by different sociocultural, biological and environmental aspects. At present, there are beauty standards based on pro-thinness models, assuming the internalization of these ideals is a risk factor for the development of alterations in body image.

Western societies construct corporal stereotypes, through processes of socialization throughout the development of men and women, which are related to the ideals of culture on aesthetics and health, which constitute a source of pressure among adolescents in order to comply with these ideals, assumed and represented in the various spaces and means of communication.

Numerous studies have found that Western trends are increasingly being disseminated by a greater number of countries, so the distortion of body image is a global problem that increasingly has a greater influence in both developed and developing countries (Vaquero et al., 2013).

Adolescence is a period of transition and psychosocial adaptation (childhood-adult) in which there are numerous physical, psychological and behavioral changes that begin at puberty (Coleman \& Hendry, 2003; Nieto, 2013). In this stage, the adolescent self-defines, self-discovers and self-creates, both sexually and generically. These processes are the result of physical transformations and hormonal changes, that modify the body structure, and affect the height, weight, shape of the parts that make up the body, and the presence or absence of certain attributes (Casas \& Ceñal, 2005; UNICEF, 2013; Guadarrama et al., 2018).

In adolescence, physical, emotional and social changes occur. Young people learn new ways of relating to others. The main psychological consequences of these changes are presented in the body self-image, because they have to do with the re-evaluation of oneself and in the search for individualization (Papalia et al., 2001).

At this stage of life, the body image becomes relevant and is strongly influenced by the affective ties that the individual has and by the opinion of his body that is returned by others and then the concern for his appearance appears, wanting to highlight the attributes that perceives positive and hide those that seem negative. Therefore, the perception of body image is subject to the influence of situations in the environment in which it is lived (IBID).

The physical changes derived from the entry into puberty provoke an increase in the adolescents' concern about their body image, which in many cases is re- 
flected in a decrease in self-esteem, especially in girls (Harter, 1990; Ramos et al., 2016). The corporal figure during adolescence is subject to notable changes and modifications that require the adolescent to continually restructure their own body image. Studies shows that, in the adolescence stage, thinness is associated with a socially positive assessment, being a symbol of beauty and success, while fatness implies feelings associated with failure and is charged with connotations negative (Cruz \& Maganto, 2002; Salazar, 2008).

The study of BI is especially relevant in the preventive field of these disorders and associated diseases. In an investigation carried out in Spain, Zagalaz et al. (2014), showed that $80 \%$ of the adolescents who participated in the study were concerned about their body image; $50 \%$ were perceived as obese, while, according to their BMI, only $25 \%$ of them presented obesity.

Although this phenomenon can occur in adolescents of both sexes, numerous studies find a greater impact on girls (e.g. Espina et al., 2001; Ramos et al., 2013; Ramos, Rivera, \& Moreno, 2012). The greatest danger that discontent with body image entails is the consequent control of weight, leading to the use of inappropriate and unhealthy methods to lost weigth, a situation that is more frequent in the case of girls (e.g. Leiderman \& Triskier, 2004; Murawski et al., 2009; Ramos et al., 2013; Vaquero et al., 2013).

In Valparaiso, Chile, Soto et al. (2013), in a study conducted with 291 adolescents aged 13 to 16 years applying two sub-scales of the Eating Disorders Inventory (EDI-2) with the aim of detecting the presence of risk factors to develop a disorder of eating behavior by and its relationship with the variables overweight, obesity and gender (Urzúa et al., 2009; Meza \& Pompa, 2013).

Soto et al. (2013) found in the first factor studied that $21.9 \%$ of women and $11.0 \%$ of men showed dissatisfaction with body image. In the search for thinness factor, women (13.0\%) presented more frequency than men $(2.1 \%)$, these differences being statistically significant. It was concluded that body dissatisfaction was positively related to BMI, so that when this is greater, greater body dissatisfaction.

Meza et al., conducted a study in 2013 with 849 young people between 11 and 16 years who, in addition to height and weight measurements, were given three instruments: Body Attitude Test (BAT) by Probst et al. (1995) and the Body Shape Questionnaire (BSQ), prepared by Cooper et al. in 1987 (Meza \& Pompa, 2013).

The results showed the presence of dissatisfaction with body image in young people who, according to the BMI, presented overweight and obesity, a situation that attracts attention because it has frequently been found in the groups that present low weight that are the most associated with eating disorders and body image (Valverde et al., 2013). There was also a relationship between dissatisfaction with body image and poor physical and emotional self-concept in women with excess weight, which places them as a vulnerable group (Meza \& Pompa, 2013). 
In a study conducted in Fresnillo, Zacatecas with 231 high school students, with the aim of identifying the relationship between BMI and body dissatisfaction in adolescents aged 12 to 15 years, compare the prevalence of dissatisfaction according to nutritional status, Sex and age, Trejo et al., found that $17.7 \%$ of the study population presented mild dissatisfaction and $4 \%$ moderate dissatisfaction. When body dissatisfaction was associated with BMI, it could be observed that as the BMI increases, dissatisfaction with body image in women is greater (Trejo et al., 2010).

In Chile, Rosas et al. (2015) Conducted a study to identify the existence of differences in the risk of eating disorders and body dissatisfaction among Mapuche and non-Mapuche students and their association with the nutritional status through Eating Attitudes Test (EAT-40) and Body Shape Questionnaire, (BSQ), finding that there are no differences between the two groups with respect to body dissatisfaction, but a statistically significant gender difference was found, greater in overweight and obese women than in men. It was concluded that risk factors for eating disorders, including HF, are affecting indistinctly rural and indigenous areas, due to social and cultural changes associated with body aesthetics and beauty canons (Rosas et al., 2015).

Guadarrama et al. (2018) they made a study in the city of Toluca, State of Mexico, Mexico, on a sample of 635 students (367 women and 268 men) of four public high schools, between 15 and 16 years old. The objective was to compare the perceived and desired CI in male and female adolescents in Mexico, taking into account the differences by sex. It was hypothesized that the perceived image will be different from that desired image in Mexican adolescents and it was considered that women would present greater dissatisfaction. In this study it was found that women are dissatisfied bodily with specific parts of their body, and want to approach canons of extreme thinness. On the other hand, the men indicated as corporal ideal to have an athletic body, with strength and virility, and a greater corporal weight; this confirms the aesthetic model of corporality desired for a male adolescent.

As can be seen, the perception of body image and body dissatisfaction have been explored in the urban population, however, in the rural population, where the indigenous Mayan speaker population and high marginalization predominate, studies are scarce, so the objective is to know the situation of satisfaction with body image in high school students of rural areas of Yucatan.

\section{Method}

Participants: A cross-sectional, quantitative study of 1432 high school students from the eastern part of the state of Yucatan, $50.6 \%$ of the participants are men and $49.4 \%$ are women. The distribution by age is $11.2 \%$ of 12 years, $25.7 \%$ of 13 years, $30.5 \%$ with 14 years, 15 years $21.6 \%$, with 16 years $7.5 \%$, with 17 years $3.1 \%$ and $4 \%$ of 18 years.

Instruments: two scales were applied 1) the Body Shape Questionnaire (BSQ) 
of Cooper, Taylor, Cooper and Fairburn, 1987 evaluated dissatisfaction with weight and body image through 34 items with six response options: never, almost never, sometimes, many times, almost always and always. It has been validated in the Mexican population, from which a cut-off point of 110 and two factors was determined, normative dissatisfaction that does not represent a risk to health and pathological dissatisfaction that causes risk behaviors such as vomiting, use of laxatives, diuretics and enemas, etc. (Cooper et al., 1987; Vázquez et al., 2011).

2) The Standard Figural Stimuli test (SFS) Thompson JK, Gray J. (1995), is used to identify the perception of the perceived and ideal body image, using nine male and female figures that progressively go from thin to obese; respondents are asked to identify their perceived body image and their ideal image, the corresponding number from 1 to 9 respectively de acuerdo a las siluetas (Figure 1). An expert researcher assigns the real figure and the dissatisfaction with the corporal image (IIC) results from the difference between the perceived image and the ideal image. The distortion of the body image (DIC) results from the difference between the perceived image and the real one assigned by the expert. To interpret them, the following classification is used: very thin, images 1 and 2; slim image 3; normal, images 4 and 5; overweight, 6 and 7 and obesity 8 and 9 . (Thompson \& Gray, 1995). The questionnaires were applied anonymously, with the informed consent of parents and participants, in order to comply with the ethical and confidentiality requirements of the data required by Regulation of the General Law of Health in Matters of Research for Health (CONBIOETICA, 2013).

Procedure: The study was carried out in localities of the interior of the state of

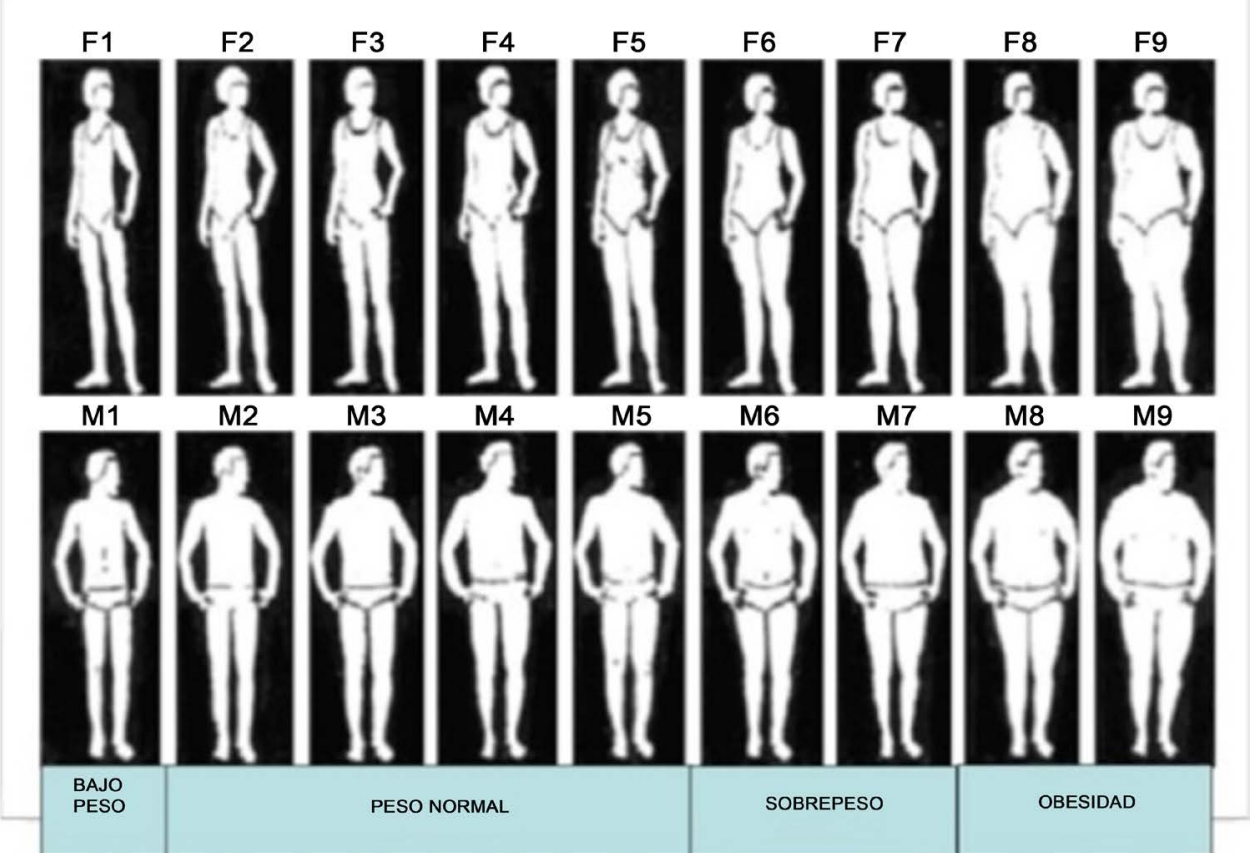

Figure 1. The standard figural stimuli test. 
Yucatan, corresponding to the Oriente region, which is characterized for containing a strong proportion of Mayan-speaking population, as well as localities of high marginalization. A random selection was made of the schools, which include all types of secondary, community, telesecundarias and public secondary schools. The sample includes 30 schools. The size of the schools ranges from 5 students enrolled to 315 students. The information was collected in the 2017-2018 school year. All classrooms and grades were invited to participate voluntarily, approximately $67 \%$ of students agreed to participate in the study. The statistical analysis was carried out using descriptive statistics, Kappa index to evaluate concordance between the real body image and the desired one, using the criteria of Landis and Koch 1977. Student's t-test is for the analysis of sex differences in dissatisfaction with body image, at a level of statistical significance of $p<0.003$.

\section{Results}

The analysis was of agreement between the real body image, with an $n=1381$, the analysis of risk of eating disorder and satisfaction with body image with $\mathrm{n}=$ 1432. The differences are due to questionnaires that do not have answers in all fields.

The expert researchers' analysis of body image perception shows that $93 \%$ is perceived between very thin and normal; of them, $52 \%$ is perceived as very thin and thin and only $7 \%$ is considered in the ranges of overweight or obesity (Graph 1).

As can be seen in Graph 2, women's perception is more focused on normality $(48.9 \%)$, to a lesser extent in very thin and in a similar proportion than men who are overweight and obese. It is worth highlighting the perception in men from

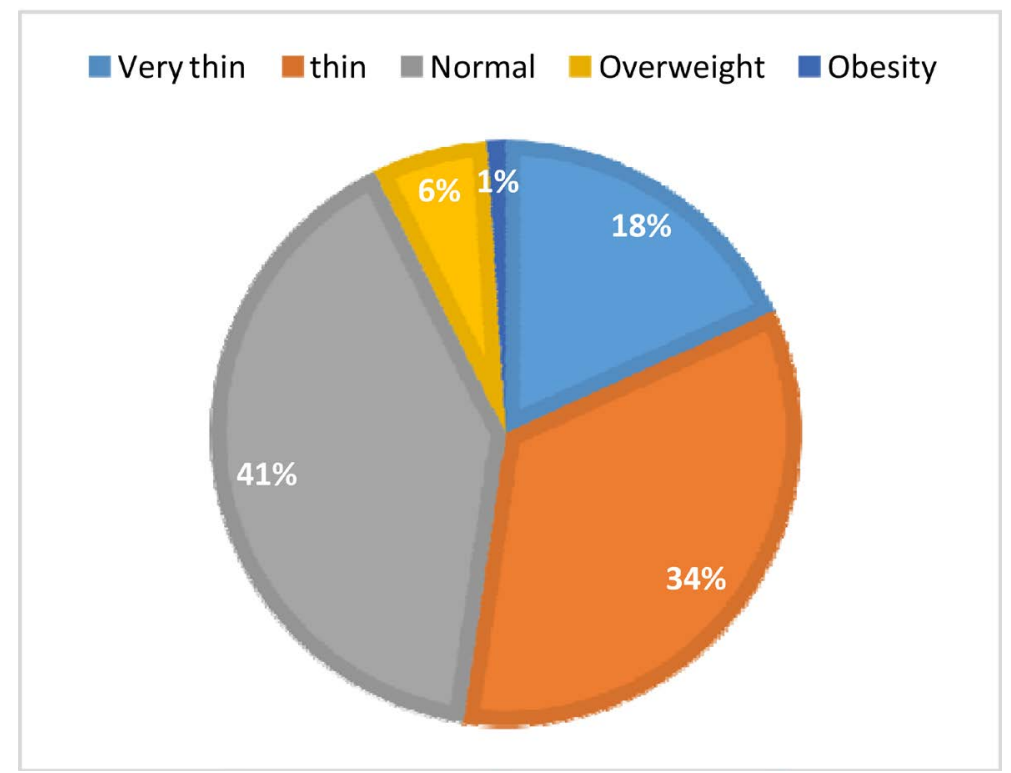

Source: result of the application in the study population of the test of the Standard Figural Stimuli (SFS) Thompson JK, Gray J. (1995).

Graph 1. Perception of body image. 
very thin to slim (60.7\%) compared to women $(43.7 \%)$.

The analysis of the coincidences between the perceived and ideal body image, is principally on the thinness and normality. The Kappa index obtained $(0.48, p$ $=0.001)$ indicates a moderate concordance (Table 1 ).

The maximum score recorded in the study was 170 points. With 105 points the percentage is $2.58 \%$, of which $67.56 \%$ are men; while, for the cut-off point of

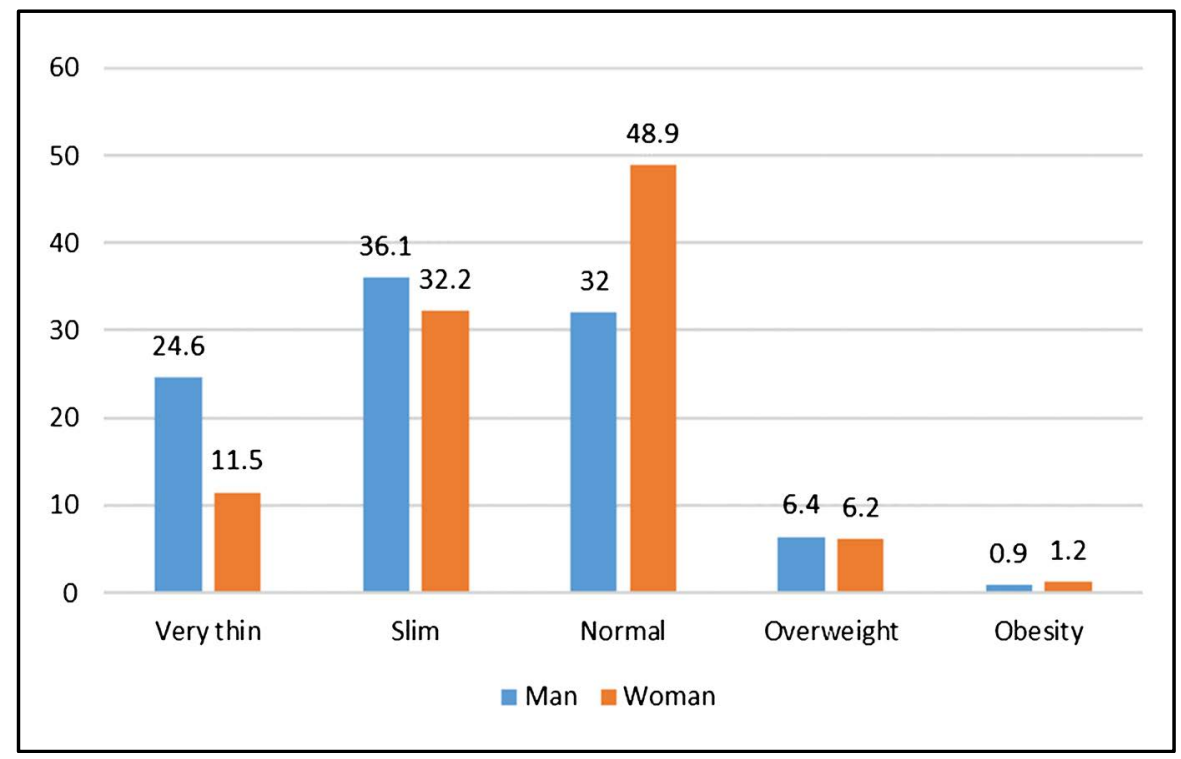

Source: Result of the application in the study population. Standard Figural Stimuli (SFS) Thompson JK, Gray J. (1995).

Graph 2. Perception of body image by sex.

Table 1. Concordance between body image percetion vs. the desired body image.

\begin{tabular}{ccccccccccc}
\hline \multirow{2}{*}{$\begin{array}{c}\text { Perceived } \\
\text { body image }\end{array}$} & $\begin{array}{c}\text { Very } \\
\text { thin }\end{array}$ & $\begin{array}{c}\text { Very } \\
\text { thin }\end{array}$ & Slim & Normal Normal & $\begin{array}{c}\text { Over } \\
\text { weight }\end{array}$ & $\begin{array}{c}\text { Over } \\
\text { weight }\end{array}$ & Obesity & Obesity & \\
\hline Very thin & 3 & 4 & 24 & 2 & 1 & 0 & 0 & 0 & 0 & 34 \\
Very thin & 2 & 24 & 176 & 13 & 3 & 1 & 0 & 0 & 0 & 219 \\
Slim & 5 & 71 & 311 & 72 & 7 & 3 & 1 & 0 & 1 & 471 \\
Normal & 2 & 29 & 257 & 86 & 16 & 1 & 0 & 0 & 0 & 391 \\
Normal & 0 & 10 & 74 & 55 & 23 & 1 & 0 & 0 & 1 & 164 \\
Over & 0 & 3 & 32 & 17 & 9 & 2 & 0 & 0 & 0 & 63 \\
weight & & & & & & & & & & \\
Over & 0 & 0 & 9 & 6 & 5 & 0 & 4 & 0 & 0 & 24 \\
weigth & & & & & & & & & & \\
Obesity & 0 & 1 & 1 & 2 & 0 & 0 & 0 & 1 & 0 & 5 \\
Obesity & 0 & 1 & 6 & 3 & 0 & 0 & 0 & 0 & 0 & 10 \\
Total & 12 & 143 & 890 & 256 & 64 & 8 & 5 & 1 & 2 & 1381 \\
\hline
\end{tabular}

Source: Result of the application in the study population. Standard Figural Stimuli (SFS) Thompson JK, Gray J. (1995). 
110 points, validated for the Mexican population, the percentage is $2.23 \%$, rank in which women obtain the highest percentage $65.63 \%$. Table 2 shows a level of satisfaction of $68.1 \%$ and distribution by score and sex ranges shows more cases of men $72.2 \%$ respect than $63.8 \%$ of women.

The analysis by sex and degree of dissatisfaction was carried out in four categories: 1) emotional attitudes towards the body image, which refers to the emotions generated around the self-concept of the body image, with emphasis on feelings of dissatisfaction; 2) Physical self-concept that is related to the parts of the body, with emphasis on those that the ideal aesthetic models of the culture impact to the dissatisfaction of the corporal image; 3) weight control attitudes are those related to weight control such as diets, vomiting, the use of medications; and 4) atitudes related to the body and social relationships based on the satisfaction and social acceptance of the body image that can lead to attitudes of isolation, complexation among others.

a) Emotional attitudes regarding body image

Satisfaction with body image is registered in $68.1 \%$ of women, which refers to positive emotional attitudes about their body image, while $30.8 \%$ registered mild to moderate dissatisfaction, and $1.1 \%$ presence of negative attitudes at the level severe or high. For men, satisfaction was $75 \%$, from mild to moderate in $24.4 \%$ and high, the value was $0.6 \%$. The analysis by sex shows significant differences $(p<0.001)$, which reveals a greater presence of negative emotional attitudes towards body image in women.

b) Physical self-concept

Women report satisfaction with body parts in $53.1 \%$, while $29.2 \%$ present mild dissatisfaction and $14.5 \%$ moderate, in addition, $3.1 \%$ report dissatisfaction with the parts of their body in a high or severe level. While men have a higher percentage of satisfaction than women with $60.5 \%$, in mild dissatisfaction $30.5 \%$, moderate 7.6 and high or severe $1.4 \%$. These differences by sex are significant, as they present lower levels of satisfaction, as well as a higher percentage in the high level of dissatisfaction $(p=0.001)$.

c) Weight control attitudes

With regard to the practices of care or weight control, women indicate in $71.9 \%$ that they do not have weight control attitudes, $19.9 \%$ resort to these practices infrequently, or a slight level, while the $7.6 \%$ declare to perform them moderately and $0.6 \%$ on a daily or frequent basis. In the case of men, $76.8 \%$ said

Table 2. Dissatisfaction by level and sex.

\begin{tabular}{ccccc}
\hline Sex & Satisfaction & Mild dissatisfaction & Moderate dissatisfaction & Severe dissatisfaction \\
\hline Men & $523(72.2)$ & $158(21.8)$ & $40(5.5)$ & $3(0.4)$ \\
Women & $452(63.8)$ & $169(23.9)$ & $80(11.3)$ & $7(1)$ \\
Total & $975(68.1)$ & $327(22.8)$ & $120(8.4)$ & $10(0.7)$ \\
\hline
\end{tabular}

Source: Result of the application in the study population. Body Shape Questionnaire (BSQ) of Cooper, Taylor, Cooper and Fairburn, 1987. 
that they do not have these attitudes to control body weight, $18.5 \%$ have them in a mild or sparse way, $4.6 \%$ in a moderate way and. $1 \%$ frequently, which indicates that there are significant differences in this type of attitude, since women have a higher percentage and level with which they perform them $(p<0.001)$.

d) Attitudes related to the body and social relationships

Attitudes based on satisfaction and social acceptance of women's body image register $65.8 \%$, with mild dissatisfaction $25 \%$, moderate $8.1 \%$ and $1.1 \%$ high or severe. In turn, men present greater satisfaction with respect to women with $72.1 \%$, in the mild level, lower percentage in women, in the moderate and high level, with $21.5 \%$ and high less than $1 \%$, differences that are not significant $(p=$ $0.004)$.

Table 3 shows the greatest dissatisfaction recorded in the physical self-concept secondly attitudes related to the body and social relationships, in third place emotional attitudes regarding body image, finally weight control attitudes.

Table 3. Body image satisfaction dimentions.

\begin{tabular}{|c|c|c|c|}
\hline Dimentions & Women & Men & $p$ Value \\
\hline Emotional attitudes regarding body image & & & $p<0.001$ \\
\hline Satisfaction & $482(68.1)$ & $543(75)$ & \\
\hline Mild dissatisfaction & $175(24.7)$ & $147(20.3)$ & \\
\hline Moderate dissatisfaction & $43(6.1)$ & $30(4.1)$ & \\
\hline Severe dissatisfaction & $8(1.1)$ & $4(0.6)$ & \\
\hline Physical self-concept & & & $p=0.001$ \\
\hline Satisfaction & $376(53.1)$ & $438(60.5)$ & \\
\hline Mild dissatisfaction & $207(29.2)$ & $221(30.5)$ & \\
\hline Moderate dissatisfaction & $103(14.5)$ & $55(7.6)$ & \\
\hline Severe dissatisfaction & $22(3.1)$ & $10(1.4)$ & \\
\hline Weight control attitudes & & & $p<0.001$ \\
\hline Satisfaction & $509(71.9)$ & $556(76.8)$ & \\
\hline Mild dissatisfaction & $141(19.9)$ & $134(18.5)$ & \\
\hline Moderate dissatisfaction & $54(7.6)$ & $33(4.6)$ & \\
\hline Severe dissatisfaction & $4(0.6)$ & $1(0.1)$ & \\
\hline $\begin{array}{l}\text { Attitudes related to the body } \\
\text { and social relationships }\end{array}$ & & & $p=0.004$ \\
\hline Satisfaction & $466(65.8)$ & $522(72.1)$ & \\
\hline Mild dissatisfaction & $177(25)$ & $156(21.5)$ & \\
\hline Moderate dissatisfaction & $57(8.1)$ & $41(5.7)$ & \\
\hline Severe dissatisfaction & $8(1.1)$ & $5(0.7)$ & \\
\hline
\end{tabular}

Source: Result of the application in the study population. Body Shape Questionnaire (BSQ) of Cooper, Taylor, Cooper and Fairburn, 1987. 


\section{Discussion}

Currently, problems related to body image in adolescents are increasing; studies related to the subject have been carried out in the urban area, where it has been found that corporal perception and dissatisfaction has permeated to ever younger ages and to all social strata, while in rural areas it has been little studied. This situation is worrisome because of its close relationship with risky eating behaviors, which are linked to several pathologies such as depression, self-esteem problems, muscular dysmorphic disorder and eating behavior disorders (Raich, 2004; Salaberria et al., 2007; Treasure \& Schmidt, 1995).

In the present study it can be affirmed that the majority of adolescents perceive themselves as thin $(34 \%)$ and normal $(41 \%)$ and very few perceive themselves as overweight and obese ( $6 \%$ and $1 \%$ respectively). These data are similar to what was found in high school students in Jaen, Spain, in a study conducted by Ortega Becerra et al. (2013) where the adolescents' perception was oriented to the thin $(26.0 \%)$ and normal $(49.7 \%)$ and to a lesser extent to overweight (9.5\%) and obesity (0\%). This situation may be due to the fact that adolescents tend to underestimate the problem of obesity and perceive a distorted body image, with a tendency toward ambiguity when referring to the subject (Martínez-Aguilar et al., 2010).

When the differentiation was made by sex, it was found that women were perceived with a normal figure in greater proportion (48.9\%) than men (32.0\%) and in the perception of a thin figure the opposite happened $(36.1 \%$ men and $32.2 \%$ women). The difference in the perception of body image between men and women is well documented, women frequently evaluate themselves above their real figure (Rodríguez \& Cruz, 2006; Figueroa-Rodríguez et al., 2010; Meza \& Pompa, 2013), while men perceive themselves more attached to reality (Thompson \& Gray, 1995).

When performing the analysis between the perception of the perceived and the desired body image, we found a concordance between both only in 33\% of the adolescents, where the highest proportion appeared in the figures thin (68.5\%) and normal (24\%) means that $67 \%$ of adolescents present discordance between their perceived and desired body image, a situation that coincides with that reported by Ortega Becerra et al. (2013) where they found a similar situation in $66.5 \%$ of their study population, noting that women are more satisfied with their body if they are thin and still want to weigh less and men are satisfied if their body is muscular and want to weigh more to have more muscle mass.

When analyzing the results of the BSQ to identify dissatisfaction with the body image, it was found that $68.1 \%$ of the adolescents did not show dissatisfaction with their body image.

Only $31.9 \%$ of adolescents presented body dissatisfaction more frequently in women (31.7\%) than in men (27.8\%). According to the classification described in the methodology, $22.8 \%$ of them show mild body dissatisfaction in a similar 
proportion between men (23.9\%) and women (21.8\%). Moderate body dissatisfaction was found in $8.4 \%$ of the participants, more frequently in women $(11.3 \%)$ than in men $(5.5 \%)$ and severe or extreme body dissatisfaction in.7\%, with little difference between men $(0.4 \%)$ and women $(0.1 \%)$.

These results differ with that found by Trejo et al. (2010), who conducted a study in 2010, with high school students in Fresnillo, Zacatecas, where they found a higher percentage of adolescents without body dissatisfaction (81.8\%). A higher proportion was also found in mild body dissatisfaction (17.7\%) and a lower proportion in moderate $(4.0 \%)$. In general, the population of this study despite being in rural areas, presented a higher frequency of body dissatisfaction including the level of severe, which could mean that despite being out of town, the mass media and social networks. They have influenced adolescents and therefore can develop risky behavior in the future, since as some authors affirm, as age increases, it is more likely to increase the proportion of adolescents with body dissatisfaction and other associated pathologies (Baile et al., 2002, Martínez \& Veiga, 2007).

Regarding the difference by sex, our results coincide with other studies where it is emphasized that women have a higher frequency of body dissatisfaction than men, probably because they are more susceptible to the influence of the fashionable body aesthetic model, where the perfect body is symbol of success in the social and economic field (Raich, 2004; Goldenberg, 2011; Jiménez-Cruz \& Silva-Gutiérrez, 2010; Soto et al., 2013). One of the examples of this susceptibility is that of the influence of journal information as an important cause in the genesis of anorexia and bulimia (Díaz-Soloaga et al., 2009).

The presence of body dissatisfaction has been associated only with the level of urban life and leads to suppose that adolescents face the results of global adolescent health care programs must integrate components such as self-esteem and body image satisfaction as key elements for the prevention of eating disorders and a higher quality of life. Rural localities are not exempt from these processes of socialization of body image that, together with social marginalization, constitutes risk factors for nutritional health, as shown in this study, $52.4 \%$ is perceived as very thin.

This study also supports the conclusion that body image dissatisfaction is a phenomenon that is explained by the condition of gender and culture, as behavioral patterns, risk behaviors and food health perspectives, which lead to women to present greater vulnerability to present health problems derived from the dissatisfaction of the body image as a result of mental and cognitive structures learned by the cultural and global environment as guidelines and ideals in body image and the experience of adolescence that in itself, it constitutes a stage of challenges, it also requires support for the formation of a positive self-concept in men and women of any context, and the school is an ideal space to support these processes and prevent damage to adolescents' health, in short and medium terms. 


\section{Conclusion}

Adolescent health care programs must integrate components such as self-esteem and body image satisfaction as key elements for the prevention of eating disorders and a higher quality of life. Rural localities are not exempt from these processes of socialization of body image that, together with social marginalization, constitutes risk factors for nutritional health; as shown in this study, $52.4 \%$ is perceived as very thin.

This study also supports the conclusion that body image dissatisfaction is a phenomenon that is explained by the condition of gender and culture, as behavioral patterns, risk behaviors and food health perspectives, which lead to women to present greater vulnerability to present health problems derived from the dissatisfaction of the body image as a result of mental and cognitive structures learned by the cultural and global environment as guidelines and ideals in body image and the experience of adolescence that in itself; it constitutes a stage of challenges; it also requires support for the formation of a positive self-concept in men and women of any context, and the school is an ideal space to support these processes and prevent damage to adolescents' health short and medium terms.

\section{Thanks}

We thank the staff of the schools, parents and participating students, as well as the support groups for the realization of this study.

\section{Conflicts of Interest}

The authors declare no conflicts of interest regarding the publication of this paper.

\section{References}

Baile, A.J., Guillén, G.F., \& Garrido, L.E. (2002). Insatisfacción corporal en adolescentes medida con el Body Shape Questionnaire (BSQ): Efecto del anonimato, el sexo y la edad. International Journal of Clinical and HealthPsychology, 2, 439-450.

Bourdieu, P. (2000). The Male Domination. Barcelana: Anagram.

Casas, J., \& Ceñal, J. (2005). Adolescent Development. Physical, Psychological and Social Aspects. Comprehensive Pediatrics, 9, 20-24. http://www.sld.cu/galerias/pdf/sitios/puericultura/desarrollo_adolescente(2).pdf

Coleman, J., \& Hendry, L. (2003). Psychology of Adolescence. Madrid: Morata.

CONBIOETICA (2013). Reglamento de la Ley General de Salud en Materia de Investigación para la Salud.

http://www.conbioetica-mexico.salud.gob.mx/descargas/pdf/normatividad/normatinac ional/10._NAL._Reglamento_de_Investigacion.pdf

Cooper, P., Taylor, M., Cooper, Z., \& Fairburn, C. (1987). The Development and Validation of the Body Shape Questionnaire. International Journal of eating Disorders, 6, 485-495.

https://doi.org/10.1002/1098-108X(198707)6:4<485::AID-EAT2260060405>3.0.CO;2-O

Cruz, S., \& Maganto, C. (2002). Body Dissatisfaction as an Explanatory Variable of Eating 
Disorders. Revista de Psicología, 20, 198-223.

Díaz-Soloaga, P., Múñiz, C., \& Cáceres Zapatero, D. (2009). Consumo de revistas de moda y efectos en la autopercepción del cuerpo de mujeres: Un estudio comparado entre España y México desde la tercera persona. Comunicación y Sociedad, 22, 221-242.

Espina, A., Ortego, M. A., Ochoa de Alda, I., German, A., \& Juaniz, M. (2001). Body Image and Eating Disorders in Basque Country Students: A Pilot study. Clinic and Health, 12, 217-235.

Figueroa-Rodríguez, A., García-Rocha, O., Revilla-Reyes, A., Villarreal-Caballero, L., \& Unikel-Santoncini, C. (2010). Modelo estético corporal, insatisfacción con la figura y conductas alimentarias de riesgo en adolescentes. Revista Médica del Instituto Mexicano del Seguro Social, 48, 31-38.

García, N. (2004). Eating Disorders in Adolescents of Both Sexes with and without Diabetes Mellitus Type I. Doctoral Thesis, Barcelona: Autonomous University of Barcelona.

Goldenberg, M. (2011). Gênero, “o corpo" e "imitação prestigiosa” na cultura brasileira [Gender, "the Body" and "Prestigious Imitation" in the Brazilian Culture]. Saúde e Sociedade, São Paulo, 20, 543-553. https://doi.org/10.1590/S0104-12902011000300002

Guadarrama, R., Hernandez-Navor, J., \& Veytia-Lopez, M. (2018). How I Perceive Myself and How I Would Like to Be: A Study on Body Image of Mexican Adolescents. Journal of Clinical Psychology with Children and Adolescents, 5, 37-43.

Harter, S. (1990). Self and Identity Development. In S. S. Feldman and G. R. Elliott (Eds.), At the Threshold: The Developing Adolescent (pp. 352-387). Cambridge, MA: Harvard University.

Horrocks, J. (1999). Adolescent Psychology (p. 128). Editorial Trillas.

Jiménez-Cruz, B. E., \& Silva-Gutiérrez, C. (2010). Riesgo para trastorno alimentario, ansiedad, depresión y otras emociones asociadas a la exposición de imágenes publicitarias. Anales de Psicología, 26, 11-17.

Landis, J., \& Koch, G. (1977). The Measurement of Observer Agreement for Categorical Data. Biometric, 33, 159-74. https://doi.org/10.2307/2529310

Leiderman, E., \& Triskier, F. (2004). Attitudes, Eating Behavior Obsessive-Compulsive Traits in Adolescents in the City of Buenos Aires. Vertex: Argentine Journal of Psychiatry, 15, 175-179.

Martínez, D., \& Veiga, O. (2007). Insatisfacción Corporal en Adolescentes: Relaciones con la Actividad Física e Índice de Masa Corporal. Internacional de Medicina y Ciencias de la Actividad Física y el Deporte, 7, 253-265.

Martínez-Aguilar, Ma. de la Luz, Flores-Peña, Y., Rizo-Baeza, Ma. de las M., Aguilar-Hernández, R. Ma., Vázquez-Galindo, L., \& Gutiérres-Sánchez, G. (2010). Percepciones de la obesidad de adolescentes obesos estudiantes del 7 al 9 grado residentes en Tamaulipas, México. Revista Latino-Americana de Enfermagem, 18, 48-53. https://doi.org/10.1590/S0104-11692010000100008

Meza, C., \& Pompa, E. (2013). Dissatisfaction with the Body Image in Adolescents of Monterrey. Daena: International Journal of Good Conscience, 8, 32-43.

Míguez, M., De la Montaña, J., González, J., \& González, M. (2011). Concordance between Self-Perception of Body Image and Nutritional Status in University Students in Orense. Hospital Nutrition, 26, 472-479.

http://scielo.isciii.es/pdf/nh/v26n3/07_original_03.pdf

Muñoz, A. (2014). The Corporal Image in the Society of the XXI Century. Thesis, Barce- 
lona: International University of Catalonia.

https://www.recercat.cat/bitstream/handle/2072/242794/Ana_Mar\%C3\%ADa_Mu\%C3 \%B1oz_L\%C3\%B3pez.pdf

Murawski, B., Elizathe, L., \& Rutsztein, G. (2009). Eating Habits and Dissatisfaction with Body Image. A Comparative Study between Women and Men Students of Secondary Schools. Research Yearbook of the Faculty of Psychology, 16, 65-72.

Nieto, F. (2013). Approach to a Mediated Adolescence. Adolescence and Postmodernity: Malestares, Vacillations and Objectives. Mexico: Fontamara.

Ortega Becerra, M. A. et al. (2013). La percepción e insatisfacción corporal en el alumnado de Educación Secundaria de la ciudad de Jaén. Revista de Investigación en Educación, 11, 123-139. http://reined.webs.uvigo.es/index.php/reined/article/view/179

Otto, M. W., Wilhelm, S., Cohen, L. S., \& Harlow, B. L. (2001). Prevalence of Body Dysmorphic Disorder in a Simple Community of Women. American Journal of Psychiatry, 158, 2061-2063. https://doi.org/10.1176/appi.ajp.158.12.2061

Papalia, D. et al. (2001). Development Psychology (pp. 280-281). Colombia: Editorial McGraw Hill.

Raich, R. (2001). Body Image Knowing and Assessing One's Own Body (pp. 24-25). Madrid: Ediciones Pirámide.

Raich, R. (2004). A Perspective from the Psychology of the Health of the Corporal Image. Advances in Latin American Psychology, 22, 15-27.

Ramos, P., Brooks, F., Garcia, I., Rivera, F., \& Moreno, C. (2013). Eating Habits and Physical Activity in Dieter and Non-Dieter Youth: A Gender Analysis of English and Spanish Adolescents. The Social Science Journal, 50, 575-582.

https://doi.org/10.1016/j.soscij.2013.09.017

Ramos, P., Rivera, F., \& Moreno, C. (2012). Key Variables in the Development of Eating Disorders during Adolescence: Implications for Sex Differences. In I. Jauregui (Ed.), Relevant Topics in Eating Disorders (pp. 31-44). Rijeka: InTech.

https://www.intechopen.com/books/relevant-topics-in-eating-disorders/key-variables-i n-the-development-of-eating-disorders-during-the

Ramos, P., Rivera, F., Soledad, R., Lara, L., \& Moreno, C. (2016). Gender Differences in Body Image and Its Relevance in Body Weight Control. Psychology Writings, 9, 42-50. https://doi.org/10.5231/psy.writ.2015.1409

Rocha (2009). Development of Gender Identity from a Psycho-Socio-Cultural Perspective: A Conceptual Journey. Interamerican Journal of Psychology, 43, 250-259.

Rodríguez, C. (2012). Self-Esteem in Adolescence: Analysis and Intervention Strategies. International Journal of Psychology and Psychological Therapy, 12, 389-403. http://www.ijpsy.com/volumen12/num3/337/self-esteem-en-la-adolescencia-analisis-E S.pdf

Rodríguez, S., \& Cruz, S. (2006). Body Image Evaluation in Latin American Women Living in Guipúzcoa. An Exploratory Study Annals of Psychology, 22, 186-199. https://www.researchgate.net/publication/39302177_Evaluacion_de_la_imagen_corpor al_en_mujeres_latinoamericanas_residentes_en_Guipuzcoa_Un_studio_exploratorio

Rosas, M., Delgado, P., Cea, F., Hormazabal, M., Alvarez, R., \& Quezada, K. (2015). Comparison of Risks in Eating Behavior Disorder and Body Image among Mapuche and Non-Mapuche Students. Nutrición Hospitalaria, 32, 2926-2931.

Salaberria, K., Rodríguez, S., \& Cruz, S. (2007). Perception of Body Image. Osasunaz, 8, 171-183.

Salazar, Z. (2008). Adolescence and Body Image in the Age of Thinness, Reflections. Re- 
flexiones, 87, 67-80. http://www.redalyc.org/pdf/729/72912555004.pdf

Soto, A., Cáceres, K., Faure, M., Gásquez, M., \& Marengo, L. (2013). Body Dissatisfaction, Thinness Search and Excess Malnutrition, a Correlational Descriptive Study in a Population of Students from 13 to 16 Years of Age in the City of Valparaíso. Revista Chilena de Nutrición, 40, 10-15.

Thompson, J., \& Gray, J. (1995). Development and Validation of a New Body-Image Assessment Scale. Journal of Personality Assessment, 64, 258-269. https://doi.org/10.1207/s15327752jpa6402_6

Treasure, J., \& Schmidt, U. (1995). The Cognitive-Interpersonal Maintenance Model of Anorexia Nervosa Revisited: A Summary of the Evidence for Cognitive, Socio-Emotional and Interpersonal Predisposing and Perpetuating Factors. Journal of Eating Disorders, 1, 13. https://doi.org/10.1186/2050-2974-1-13

Trejo, P., Castro, D., Facio, A., Mollinedo, F., \& Valdez, G. (2010). Dissatisfaction with the Body Image Associated with the Body Mass Index in Adolescents. Revista Cubana de Enfermeria, 26, 144-154. http://scielo.sld.cu/pdf/enf/v26n3/enf07310.pdf

UNICEF (2013). Adolescence. https://www.unicef.org/mexico/spanish/ninos_6879.htm

Urzúa, A., Castro, S., Lillo, A., \& Leal, C. (2009). Evaluation of Eating Disorders, Psychometric Properties of the EDI 2 Test in School-Aged Adolescents from 13 to 18 Years Old. Revista Chilena de Nutrición, 36, 1063-1073.

Valverde, P., Rivera, F., \& Moreno, C. (2013). Sex Differences in Body Image, Weight Control and Body Mass Index in Spanish Adolescents. Psicothema, 22, 77-83.

Vaquero, R., Alacid, F., Muyor, J. M., \& Lopez, P. (2013). Body Image; Bibliographic Review. Hospital Nutrition, 28, 27-35.

Vázquez, R., Galan, Y., Lopez, X., Alvarez, G., Mancilla, J., Caballero, A. et al. (2011). Validity of the Body Shape Questionnaire (BSQ) in Mexican Women. Rev Mex Eating Disorders, 2, 42-52.

Vázquez, R., López, X., Álvarez, G., Franco, K., \& Mancilla, J. (2004). Presence of Eating Disorders in Mexican Men and Women: Some Associated Factors. Behavioral Psychology, 12, 415-427.

https://www.researchgate.net/profile/Karina_Franco-Paredes/publication/267699093

Zagalaz, M., Romero, S., \& Contreras, O. (2014). Anerexia Nervosa as a Distortion of Body Image. Program of Prevention from School Physical Education in the Province of Jaén. Iberoamerican Journal of Education, 1-22.

http://rieoei.org/deloslectores/343Zagalaz.pdf 